\title{
In vitro effects of endothelin-1 on the contractility of myometrium obtained from pre- and postmenopausal women
}

\author{
E Domali $^{1,2}$, E Asprodini ${ }^{3}$, P A Molyvdas ${ }^{2}$ and I E Messinis ${ }^{1}$ \\ ${ }^{1}$ Department of Obstetrics and Gynecology, University of Thessalia, 22 Papakiriazi Street, 41222 Larissa, Greece \\ ${ }^{2}$ Department of Physiology, University of Thessalia, 22 Papakiriazi Street, 41222 Larissa, Greece \\ ${ }^{3}$ Department of Pharmacology, University of Thessalia, 22 Papakiriazi Street, 41222 Larissa, Greece \\ (Requests for offprints should be addressed to I E Messinis)
}

\begin{abstract}
This study was conducted to evaluate the responsiveness of human nonpregnant myometrium to endothelin 1 (ET1) $\left(10^{-10} \mathrm{M}-10^{-6} \mathrm{M}\right)$ and $\mathrm{KCl}(80 \mathrm{mM})$ in relation to the hormonal profile of the women, who were allocated into three groups: group 1, premenopausal follicular phase, $n=14$, group 2 , premenopausal luteal phase, $n=20$, and group 3, postmenopausal women, $n=12$. At a concentration of $10^{-6} \mathrm{M}$, ET1 in both groups 1 and 2 induced very low ripples of high frequency (group 1: $80 \pm 14 \%$, $n=5$, group 2: $314 \pm 63 \%, n=11 ; P<0 \cdot 05$ compared with the pretreatment frequency) which lasted significantly longer in group $2(29 \pm 2 \mathrm{~min}, n=10, P<0 \cdot 05)$ than in group $1(20 \pm 2 \mathrm{~min}, n=5)$, increasing the basal tone (group 1: $57 \cdot 9 \pm 6 \%, n=5$, group 2: $64 \cdot 4 \pm 4 \%, n=6$ ), the amplitude of myometrial contractility (group 1: $1 \cdot 2 \pm 0.07 \mathrm{~g}, n=5$, group 2: $1.6 \pm 0.1 \mathrm{~g}, n=7, P<0 \cdot 05)$ and the area under the contractility curve (AUC; group 1 : $8.4 \pm 1.1 \mathrm{~g} \times \min , n=6$, group $2: 11.9 \pm 1.6 \mathrm{~g} \times \mathrm{min}$, $n=11)$. In group 3 , ET1 $\left(10^{-6} \mathrm{M}\right)$ created a sustained long-lasting contraction (initial phase: $43 \pm 6 \mathrm{~min}, n=6$ ) characterized by the complete obliteration of spontaneous contractility with no ripples at all, and increasing significantly $(P<0 \cdot 05)$ the amplitude of myometrial contractility
\end{abstract}

$(2 \cdot 8 \pm 0 \cdot 5 \mathrm{~g}, n=6)$, the AUC $(24 \cdot 7 \pm 3 \cdot 3 \mathrm{~g} \times \min , n=6)$, as well as the basal tone $(183 \cdot 6 \pm 21 \%, n=6)$ compared with the two premenopausal groups. In all three groups $\mathrm{KCl}$ exposure induced an initial rise (mean amplitude value: $1 \cdot 1 \mathrm{~g})$ followed by a relaxation phase to the primal baseline level (mean duration value: $12 \mathrm{~min}$ ). Addition of ET1 $\left(10^{-6} \mathrm{M}\right)$ to $\mathrm{KCl}(80 \mathrm{mM})$ induced a similar pattern of contractility to that evoked by ET1 alone which, compared with $\mathrm{KCl}$ alone lasted significantly longer $(P<0 \cdot 05)$ in all three groups (group 1: $20 \pm 2 \mathrm{~min}, n=6$; group 2: $23 \pm 2 \mathrm{~min}, n=6$; group 3: $35 \pm 3 \mathrm{~min}, n=5$ ). In group 3 , the percentage change in basal tone was significantly smaller following $\mathrm{KCl}$ than after the combination of $\mathrm{KCl}$ plus ET1 $(149 \pm 16 \%, n=5 ; P<0 \cdot 01)$, indicating a different mechanism of contractility between $\mathrm{KCl}$ and ET1. These results demonstrate for the first time differences in myometrial response to ET1 between pre- and postmenopausal women. It is suggested that $\mathrm{KCl}$ and $\mathrm{ET} 1$ affect uterine contractility through different mechanisms and that ovarian steroids may play a regulatory role in human uterine responsiveness to ET1.

Journal of Endocrinology (2001) 168, 153-162

\section{Introduction}

Endothelins (ETs) consist of a family of three sarafotoxinlike peptides ET1, ET2 and ET3 originally isolated from the supernatant of cultured porcine endothelial cells (Yanagisawa et al. 1988). They are produced by different cell types, endothelial and epithelial cells (Ohkubo et al. 1990, Sakurai et al. 1991, Kamada et al. 1992) and are primarily described for their potent vasoconstrictor actions (Davenport et al. 1990, Bodelsson et al. 1996, Elchalal \& Schenker 1997). It has also been reported that ETs modulate the contractility in a variety of tissues. The effects of ETs are mediated through two cloned and sequenced subtypes of receptors, ETA and ETB, which are members of the G-protein-linked receptor superfamily (Masaki et al. 1994); ET1 is a selective ligand for ETA receptor $(\mathrm{ET} 1>\mathrm{ET} 2)$, whereas the three peptides, ET1, ET2 and ET3 have been reported to display equal affinity for $\mathrm{ETB}$ receptor $(\mathrm{ET} 1=\mathrm{ET} 2=\mathrm{ET} 3$ ) (Arai et al. 1990, Sakurai et al. 1990, 1992, Bacon et al. 1995).

In particular, the 21-amino acid peptide, ET1, is a potent, long-acting vasoconstrictor and proliferative agent produced by a wide range of human cell types (Sunnergen et al. 1990, Marciniak et al. 1992, Casey \& MacDonald 1996) and plays a functional role in the female reproductive system (Kamada et al. 1993, Haq et al. 1996, Apa et al. 1998). Northern blot analysis demonstrated the release of ET1 by human decidual cells in early pregnancy 
(Kubota et al. 1992) and the presence of immunoreactive prepro ET1 and prepro ET1 mRNA in human endometrial tissue (Economos et al. 1992, Salamonsen et al. 1992, Cameron et al. 1992, 1993, Marsh et al. 1994). It has been reported that the binding sites for ET1 are distributed in the human uterus throughout the menstrual cycle (O'Reilly et al. 1992) and that both subtypes of receptors are localized in human myometrium, where ETA binding sites represent the principal subtype (Schiff et al. 1993, Breuiller-Fouche et al. 1994, Pekonen et al. 1994, Wolff et al. 1996). It has been demonstrated that in human nonpregnant myometrium, ET1 induces contractions (Word et al. 1990, Fried et al. 1993, Svane et al. 1993) activating exclusively the ETA receptors, and increasing the two phases of spontaneous myometrial contractility, the phasic and the tonic phase, despite the lesser sensitivity of nonpregnant compared with pregnant myometrium (Word et al. 1991, Osada et al. 1997). Although binding studies have shown that ET1 exhibits affinity for ETB receptors, activation of ETB sites, using ETB selective ligands, has not been reported to mediate any contractile effect on human myometrial tissue; the lack of any contractile effect on human nonpregnant uterus has been attributed to the small population of ETB receptors (less than $25 \%$ ) on human myometrium, or to their involvement in mechanisms of relaxation and proliferation; the precise role of ETB subtypes of receptors in human uterus needs to be further elucidated (Maggi et al. 1994, Bacon et al. 1995, Heluy et al. 1995, Wolff et al. 1996, Osada et al. 1997). However, in none of these studies has the effect of ET1 on myometrial contractility been examined specifically in relation to the hormonal profile of the women. Knowing that human uterus is a target organ of sex steroids, the purpose of our study was to elucidate the effect of ET1 on human uterine contractility in relation to the sex steroid milieu of the women, and to determine possible alterations in premenopausal women (follicular or luteal phase of the normal menstrual cycle) and in postmenopausal women.

\section{Materials and Methods}

\section{Specimens}

Myometrial tissue was collected from women undergoing hysterectomy for benign gynecological disorders. Informed consent was obtained. All women were operated on under the same conditions in terms of premedication and anesthetic drugs. None of the patients had been taking any type of hormonal therapy for the previous three months. The samples were excised with a scalpel from the anterior and the posterior surface of the body of the uterus (macroscopically normal muscle), placed in ice-cold Krebs' solution and taken immediately to the laboratory. The tissues collected from the women were allocated into three groups on the basis of the hormonal profile defined from the first day of their last menstrual period, and from serum progesterone and estradiol concentrations measured by enzyme linked fluorescent assay (ELFA) in peripheral blood samples obtained early in the morning of the day of the operation (means \pm S.E.M.); group 1: premenopausal women in the follicular phase, mean estradiol value $222.4 \pm 42 \mathrm{pmol} / 1$, mean progesterone value $1 \cdot 7 \pm 0 \cdot 1 \mathrm{nmol} / 1$ (age: $40-45$ years, $n=14$ ); group 2: premenopausal women in the luteal phase, mean estradiol value $653.5 \pm 141 \mathrm{pmol} / 1$, mean progesterone value $57 \cdot 1 \pm 31 \mathrm{nmol} / 1$ (age: $40-45$ years, $n=20$ ); group 3: postmenopausal women, estradiol value $<87 \cdot 2 \mathrm{pmol} / 1$, progesterone value $<1.3 \mathrm{nmol} / 1$ (age: $65-70$ years, $n=12$ ).

\section{Experiments}

The experiments were performed and completed within the first $10 \mathrm{~h}$ after the removal of the uterus from the abdomen, most usually within the first $6-7 \mathrm{~h}$. The viability of the tissue under investigation was confirmed by the responsiveness of human myometrium to $\mathrm{KCl}$ $(80 \mathrm{mM})$ at the end of each experiment. The specimens were immediately dissected into longitudinal strips of $5 \times 2 \times 1 \mathrm{~mm}$ parallel to the muscle fiber orientation. Briefly, the strips were mounted horizontally in bathing chambers for isometric recording with one end fixed and the other attached to an isometric transducer connected to an amplifier. An initial resting tension of $1 \mathrm{~g}$ was applied to each strip. The tissues were continuously perfused with Krebs' solution at $37{ }^{\circ} \mathrm{C}$, gassed with $95 \% \mathrm{O}_{2}$ and $5 \%$ $\mathrm{CO}_{2}$. Tension generated by the muscle strips was recorded on a GRASS FTO3C. force displacement transducer and displayed on a universal oscillograph (Harvard) recorder. During the experiments, the strips were allowed to equilibrate for 1 to $2 \mathrm{~h}$ until the spontaneous contractility became regular in frequency and intensity. The tissues were then exposed to the various stimuli for $7 \mathrm{~min}$, and washed out with Krebs' solution. The duration of the drug application in our experimental procedure was dictated by two factors: first, the time required for the superfusing solution to reach steady-state concentration within the bath, and secondly the high cost of ET1. Therefore, the 7-min application period used in our experiments was considered a satisfactory period of time to ascertain the achievement of the full effect of the drug, and at the same time to limit the cost of the experiment. Two types of experiment were performed. In the first series of experiments five different concentrations of ET1 $\left(10^{-10} \mathrm{M}\right.$, $10^{-9} \mathrm{M}, 10^{-8} \mathrm{M}, 10^{-7} \mathrm{M}, 10^{-6} \mathrm{M}$ ) were applied separately on each strip; the strips used during each experiment were from the same uterus (group 1: $n=6$ uteri, group 2: $n=11$ uteri, group 3: $n=6$ uteri). In the second series of experiments each strip was exposed to $\mathrm{KCl}$ $(80 \mathrm{mM})$, allowed to re-equilibrate for $30 \mathrm{~min}$ at least and were then exposed to different concentrations of the combination of $\mathrm{KCl}$ and ET1. The latter was used at 


\section{a. Case I}
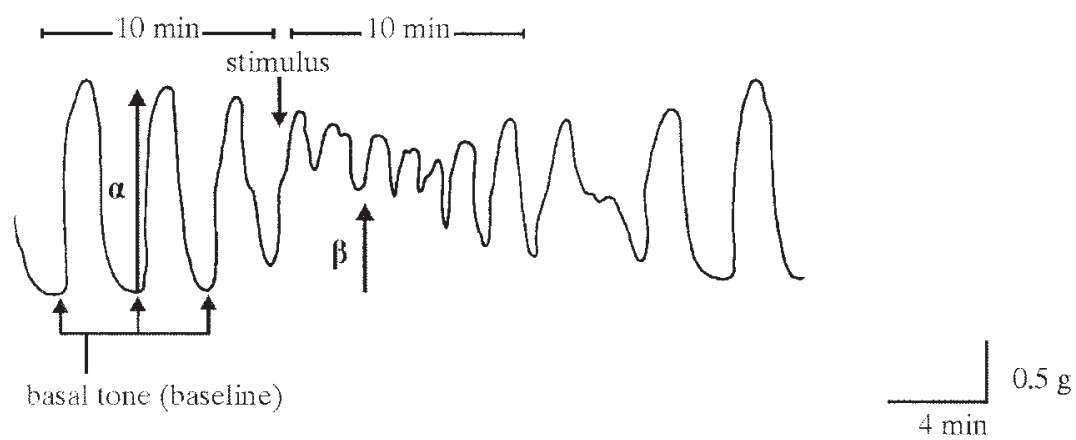

\section{b. Case II}

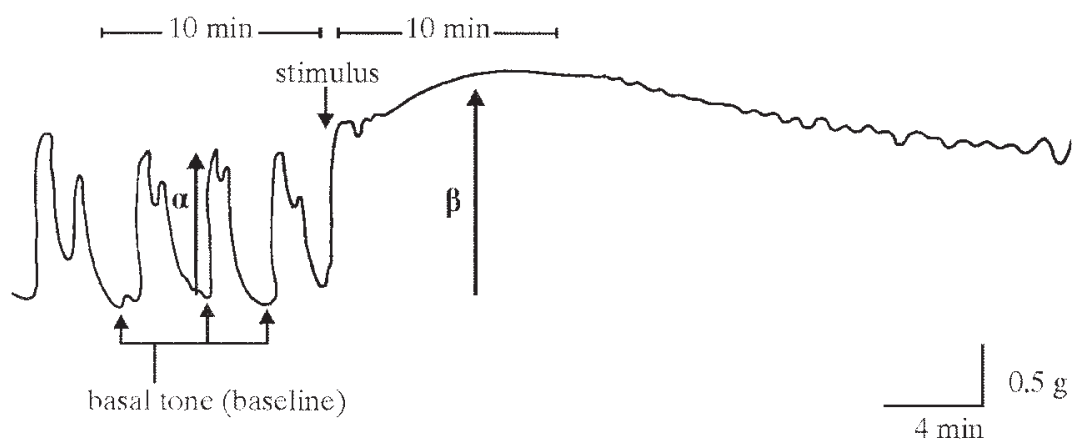

Figure 1 The change in basal tone of our preparations after 10-min treatment with the stimuli ((a) premenopausal women; (b) postmenopausal women). The alterations in basal tone observed during the experiments were calculated using the formula: $x=\beta / \alpha \times 100$, where $x$ is the percentage change in the basal tone, $\alpha$ is the mean amplitude values of spontaneous myometrial contractions, and $\beta$ is the mean distance of the lower parts of the induced contractions from the initial baseline.

concentrations of $10^{-10} \mathrm{M}, 10^{-9} \mathrm{M}, 10^{-8} \mathrm{M}, 10^{-7} \mathrm{M}$, and $10^{-6} \mathrm{M}$ (group 1: $n=8$ uteri, group 2: $n=9$ uteri, group 3: $n=6$ uteri). To evaluate the contractile activity generated and the possible alterations before and after tissue treatment with the stimuli (namely $\mathrm{KCl}, \mathrm{ET} 1$ or the combination of $\mathrm{KCl}$ and $\mathrm{ET} 1$ ), a number of parameters were studied.

Change in basal tone The change in basal tone in the immediate 10-min period after tissue treatment with the stimulus was expressed as the percentage of the mean amplitude of the spontaneous contractions occurring in the 10-min period preceding the addition of the stimuli. Basal tone was defined as the lowest point (baseline) of the spontaneous contractions before the application of the stimuli (Fig. 1). The amplitude of the spontaneous contractions was chosen because it expresses the contractile potential of each myometrial strip. The change in basal tone was calculated as shown in the examples in Fig, 1 using the formula $x=\beta / \alpha \times 100$ where $x$ is the percentage change in the basal tone, $\alpha$ is the mean amplitude of the spontaneous myometrial contractions, and $\beta$ is the mean values of the distance of the lower parts of the induced contractions from the initial baseline. In case I, $\alpha=1.94 \mathrm{~g}, \beta=0.842 \mathrm{~g}$ and $\mathrm{x}=43.4 \%$, i.e. application of the stimulus raised the basal tone by $43.4 \%$ of the amplitude of the contractions preceding the stimulus. In case II, $\alpha=1.335 \mathrm{~g}, \beta=1.891 \mathrm{~g}$ and $\mathrm{x}=141.6 \%$, i.e. tissue treatment with the stimulus elevated the basal tone by $141 \cdot 6 \%$ of the amplitude of the contractions preceding the stimulus.

Frequency of myometrial contractility Frequency of myometrial contractility in a 20-min period after tissue treatment with the stimulus was expressed as the percentage change in the sum of spontaneous contractions occurring in a period of $20 \mathrm{~min}$ before the application of the stimulus.

The area under the contractility curve The area under the contractility curve (AUC) was determined as the integrated force from the start of the induced contraction up to $10 \mathrm{~min}$ from the application of the stimulus and was quantified by planimetry of the included area. 

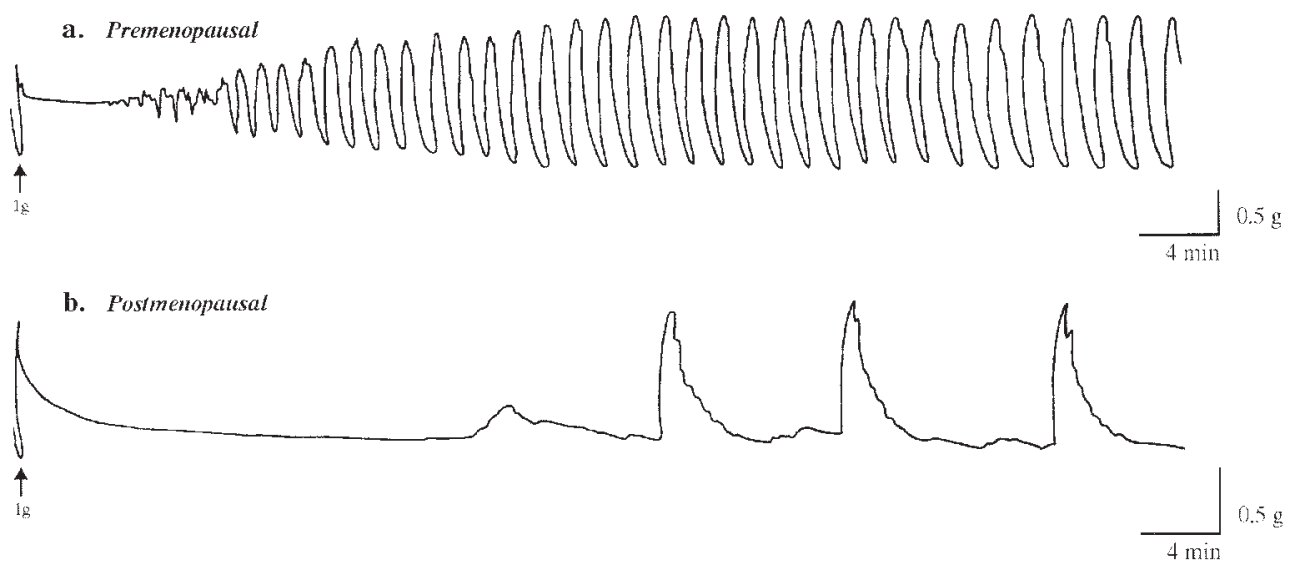

Figure 2 Representative traces of spontaneous myometrial contractility evoked after the application of $1 \mathrm{~g}$ resting tension in strips obtained from (a) premenopausal and (b) postmenopausal women. In postmenopausal preparations spontaneous contractions appeared later, after $30 \mathrm{~min}$ on average compared with 2-3 min in both groups 1 and 2 (premenopausal women).

The amplitude of myometrial contractility The amplitude of myometrial contractility was defined as the value of the distance between the highest point and the initial baseline of the evoked contractility in a period of 10 min after the application of each stimulus.

\section{Duration of alterations in myometrial contractility}

The duration of alterations in the myometrial contractility after the addition of each stimulus was determined as the period of time from the application of the stimulus until the reappearance of relatively regular spontaneous contractility.

\section{Reagents}

The stock solution consisted of a mixture of ET1 $(0 \cdot 1 \mathrm{mg})$ with $4 \mathrm{ml}$ distilled water resulting in an ET1 concentration of $10^{-5} \mathrm{M}$. The concentrations of ET1 used in our experiments were prepared with sequential dilutions of the initial stock solution. ET1 $(0 \cdot 1 \mathrm{mg})$ was purchased from SIGMA-ALDRICH CHEMIE, GmbH P.O. 1120, 89552 Stenheim, Germany. The ionic composition of the modified Krebs' solution was as follows: $\mathrm{NaCl} 110.9 \mathrm{mM}$, $\mathrm{KCl} \quad 5.9 \mathrm{mM}, \quad \mathrm{MgCl}_{2} \quad 1.1 \mathrm{mM}, \quad \mathrm{CaCl}_{2} \quad 2 \mathrm{mM}$, $\mathrm{NaH}_{2} \mathrm{PO}_{4} \cdot \mathrm{H}_{2} \mathrm{O} 1.2 \mathrm{mM}$, glucose $9.6 \mathrm{mM}$, $\mathrm{NaHCO}_{3}$ $25 \mathrm{mM}$. Drugs were purchased from E. Merck, D-6100 Darmstadt, F.R. Germany, except for glucose and $\mathrm{NaHCO}_{3}$ which were purchased from Mallinckrodt Chemical Works, St Louis, MO, USA and Mallinckrodt Baker B.V., Deventer, Holland respectively.

\section{Hormone assays}

Blood samples were centrifuged at 3000 cycles/min at least. The serum was extracted from the supernatant and assayed in an automated multiparametric immunoanalyzer; the analyzer functions on the basis of a technical method (ELFA), which combines enzyme immunoassay with fluorescent reading $(450 \mathrm{~nm})$. The immunoanalyzer and the reagents were purchased from bioMerieux sa 69280 , Marcy-l'Etoile, Paris, France.

\section{Statistical analysis}

The responses of the human myometrium to different stimuli (KCl, ET1, or $\mathrm{KCl}$ and ET1) were compared by one-way analysis of variance. Mean values and standard errors of the mean (means \pm s.E.M.) were determined, and the statistical significance was confirmed by the use of the Student's unpaired $t$-test, where appropriate.

\section{Results}

During tissue equilibration, segments collected from premenopausal women (follicular phase, $n=14$; luteal phase, $n=20)$ showed excessive spontaneous motility compared with those collected from postmenopausal women $(n=12)$. In premenopausal women, spontaneous contractions were revealed immediately (within $2-3$ min) after the application of $1 \mathrm{~g}$ tension and they increased progressively in amplitude and frequency (Fig. 2a). In postmenopausal women, myometrium contracted spontaneously much later $(30 \mathrm{~min})$, and the frequency of the contractions was lower than in the premenopausal groups (Fig. 2b).

During the first series of experiments, the effect of ET1 was evaluated on human uterine muscle strips. At concentrations ranging from $10^{-10} \mathrm{M}$ to $10^{-7} \mathrm{M}$, ET1 induced a dose-dependent increase in the frequency of the contractions in tissues collected from premenopausal women without any statistically significant difference between groups 1 and 2. At a concentration of $10^{-6} \mathrm{M}$, ET1 in 

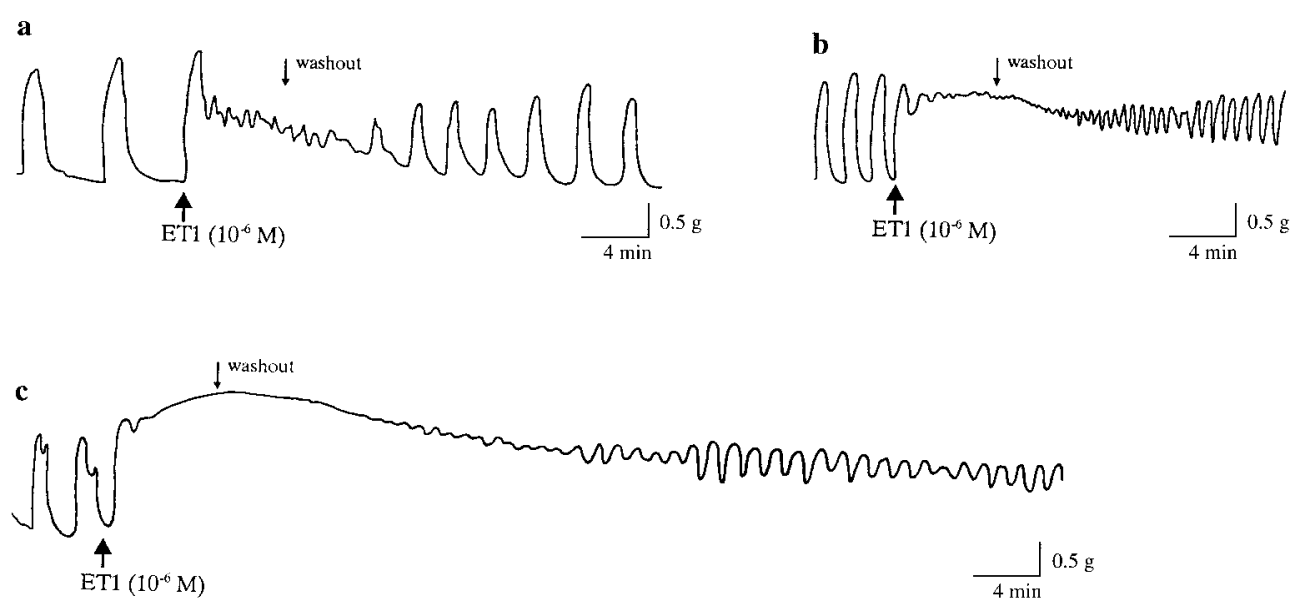

Figure 3 Representative traces showing alterations in human spontaneous myometrial contractility after treatment with ET1 at a concentration of $10^{-6} \mathrm{M}$ in (a) group 1, premenopausal women, follicular phase $(n=6)$, (b) group 2, premenopausal women, luteal phase $(n=11)$ and (c) group 3, postmenopausal women $(n=6)$. In the premenopausal groups, ET1 altered the pattern of spontaneous myometrial contractility, inducing very low ripples of high frequency, which lasted longer in group 2 than in group 1; in group 3, ET1 induced a sustained long-lasting contraction with no ripples at all which lasted much longer than those in both groups 1 and 2 .

both groups 1 and 2 caused a change in the pattern of myometrial contractility (Fig. 3), increasing the basal tone and inducing very low ripples of high frequency. Compared with the pretreatment frequency, an increase in group 1 of $80 \pm 14 \%(n=5)$ and in group 2 of $314 \pm 63 \%$ $(n=11, P<0.05)$ was found. The increase in basal tone was greater in group 2, in which the ripples were less discernible, than in group 1 (Fig. 3a and b). The height of the ripples increased gradually in both groups before regular contractility was re-established. The change in myometrial contractility up to the time of onset of regular contractions lasted significantly longer in group 2 $(29 \pm 2 \mathrm{~min}, n=10)$ than in group $1(20 \pm 2 \mathrm{~min}, n=5$, $P<0 \cdot 05)$. During the period of re-establishment of regular contractions, the frequency of contractions was still higher than before the treatment with ET1, especially in group 2; in other words, the appearance of regular contractions was achieved quicker in group 1 than in group 2 (Fig. 3a,b). In postmenopausal women (group 3), the application of the lower concentrations $\left(10^{-10} \mathrm{M}, 10^{-9} \mathrm{M}, 10^{-8} \mathrm{M}\right)$ of ET1 showed no significant effect on the frequency of the evoked contractions. At concentrations of $10^{-7} \mathrm{M}$ and particularly at $10^{-6} \mathrm{M}$, as in groups 1 and 2, ET1 caused a remarkable change in the pattern of myometrial contractility which, however, differed from that in the other two groups in that the action of ET1 resulted in a sustained long-lasting contraction, the initial part of which lasted $43 \pm 6 \min (n=6)$ and was characterized by the complete obliteration of spontaneous contractility with no ripples at all (Fig. 3c). Following this, ripples appeared without any sign of onset of regular contractility for a period of at least $2 \mathrm{~h}$. This pattern was closer to that in group 2, but in group 3 the basal tone increased further and the change lasted much longer.

Application of $\mathrm{KCl}(80 \mathrm{mM})$ alone to myometrial strips (Fig. 4) evoked a contraction characterized by an initial rise followed by a slow relaxation phase to the initial baseline level which lasted on average $12 \mathrm{~min}$ with no significant difference between the three groups. Addition of ET1 $\left(10^{-6} \mathrm{M}\right)$ and $\mathrm{KCl}(80 \mathrm{mM})$ induced a pattern of contractility which was similar to that induced by ET1 alone with no significant difference between the corresponding groups. Compared, however, with the contractile pattern evoked by $\mathrm{KCl}$ alone, the combination of $\mathrm{KCl}$ and ET1 significantly increased the duration of change in myometrial contractility $(P<0 \cdot 05)$ in groups $1(20 \pm$ $2 \min , n=6)$, and $2(23 \pm 2 \mathrm{~min}, n=6)$, while in group $3(35 \pm 3 \mathrm{~min}, n=5)$ regular myometrial motility was re-established much later $(P<0 \cdot 01)$ than in the two premenopausal groups (Fig. 4a,b,c).

Table 1 compares the amplitude of myometrial contractility, the AUC, and the percentage increase in basal tone during application of $\mathrm{KCl}$ alone, ET1 alone, and the combination of $\mathrm{KCl}$ and $\mathrm{ET} 1$ in the three groups. A dose-response effect of ET1 on AUC was found (Fig. 5). Treatment with ET1 alone $\left(10^{-6} \mathrm{M}\right)$ induced amplitude and AUC values that did not differ significantly between groups 1 and 2, but were significantly greater $(P<0 \cdot 01)$ in group 3 compared with the two premenopausal groups (Table 1). Addition of ET1 to $\mathrm{KCl}$ significantly restricted $(P<0 \cdot 05)$ the myometrial responsiveness induced by ET1 alone only in group 3. Normalization of the data to $\mathrm{KCl}$ confirmed the statistical differences between the groups (Fig. 6). This significant attenuation should be attributed 

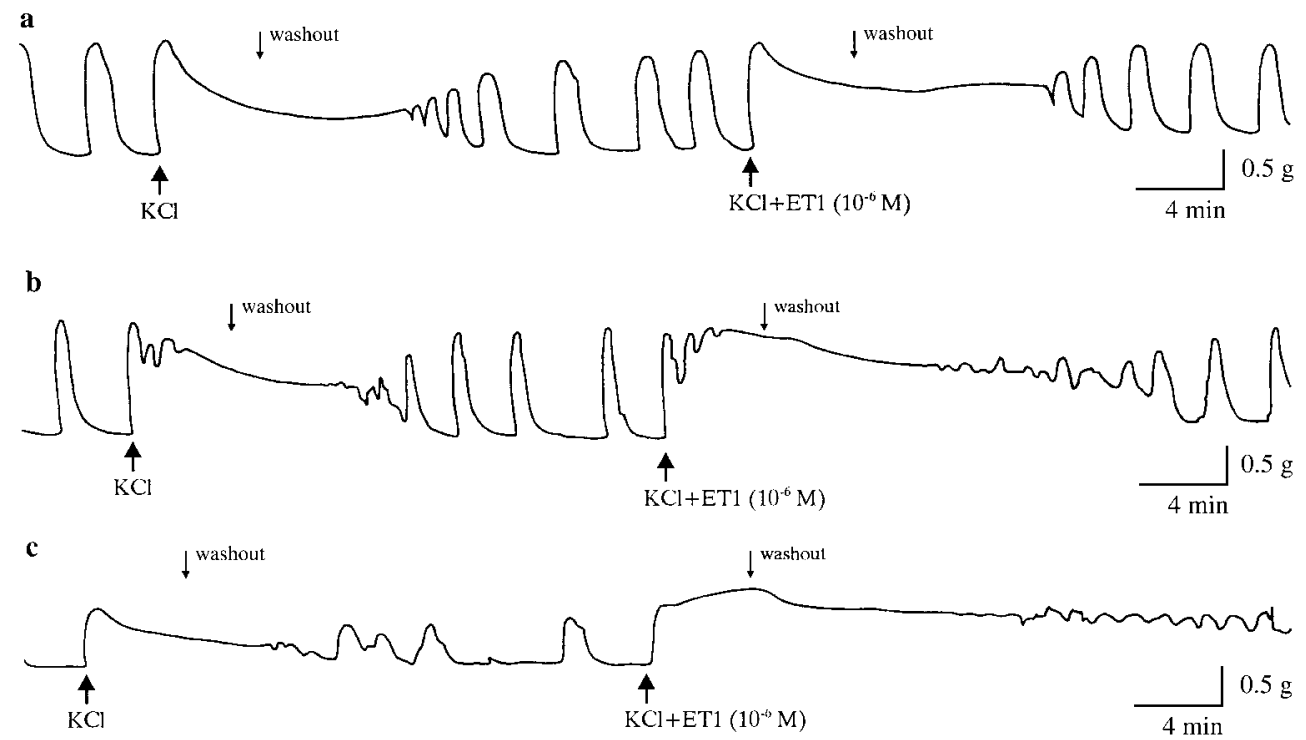

Figure 4 Representative traces showing the effects of $\mathrm{KCl}$ alone $(80 \mathrm{mM})$ and the combination of $\mathrm{KCl}$ and ET1 at a concentration $10^{-6} \mathrm{M}$ on human myometrial contractility in (a) group 1, premenopausal women, follicular phase $(n=8)$, (b) group 2, premenopausal women, luteal phase $(n=9)$ and (c) group 3, postmenopausal women $(n=6)$. Addition of ET1 extended significantly the contractile pattern induced by $\mathrm{KCl}$ in group 2 and especially in group 3.

Table 1 Alterations in the amplitude of myometrial contractility, the area under the contractility curve (AUC), and the basal tone induced by $\mathrm{KCl}, \mathrm{ET} 1$, and the combination of $\mathrm{KCl}$ plus ET1 at a concentration $10^{-6} \mathrm{M}$ in premenopausal (group 1, follicular phase; group 2, luteal phase) and postmenopausal (group 3) women

Group 1

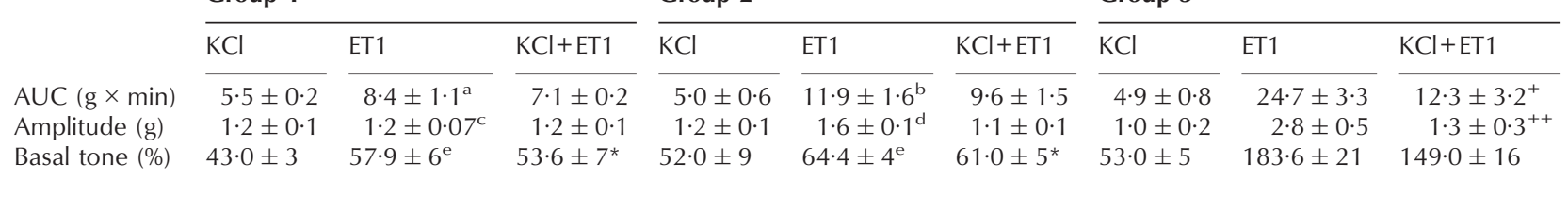

${ }^{a} P<0.001,{ }^{b} P<0 \cdot 01, \overline{{ }^{c} P<0.001,}{ }^{d} P<0.05,{ }^{e} P<0.001$ compared with group 3 (ET1); ${ }^{+} P<0 \cdot 05,{ }^{++} P<0.05$ compared with ET1 of group 3 ; ${ }^{*} P<0 \cdot 05$ compared with group $3(\mathrm{KCl}$ and $\mathrm{ET} 1)$.

to the smaller amplitude of spontaneous contractions that occurred for technical reasons during the period preceding the application of the stimulus in strips obtained from postmenopausal women as compared with premenopausal women (Table 2). In fact, when the data were analyzed on the basis of basal tone, expressed as the percentage change in myometrial contractility induced by the stimuli, this difference was eliminated. In particular, we found that ET1 in both premenopausal groups elevated the initial baseline, without significant differences between them, while in postmenopausal women (group 3) the percentage increase in basal tone was significantly greater than in the other two groups. Addition of ET1 to $\mathrm{KCl}$ did not affect the elevation in basal tone induced by ET1 alone in any of the three groups, which remained significantly $(P<0 \cdot 05)$ greater in group 3 compared with groups 1 and 2 (Table 1). Similarly, although the amplitude and the AUC induced by $\mathrm{KCl}$ alone were significantly smaller in group
3 than in groups 1 and 2, the percentage increase in basal tone induced by $\mathrm{KCl}$ did not differ significantly between the three groups (Table 1). In group 3, the percentage change in basal tone was significantly smaller following $\mathrm{KCl}$ than following ET1 or the combination of $\mathrm{KCl}$ plus ET1. No significant correlations were found between estradiol or progesterone concentrations and the contractile parameters used on an individual basis.

\section{Discussion}

This study demonstrates significant changes in the spontaneous contractility of human nonpregnant myometrium evoked by ET1 in postmenopausal and premenopausal women. The main finding of the study was the longlasting effectiveness of ET1 in strips collected from postmenopausal women compared with premenopausal 

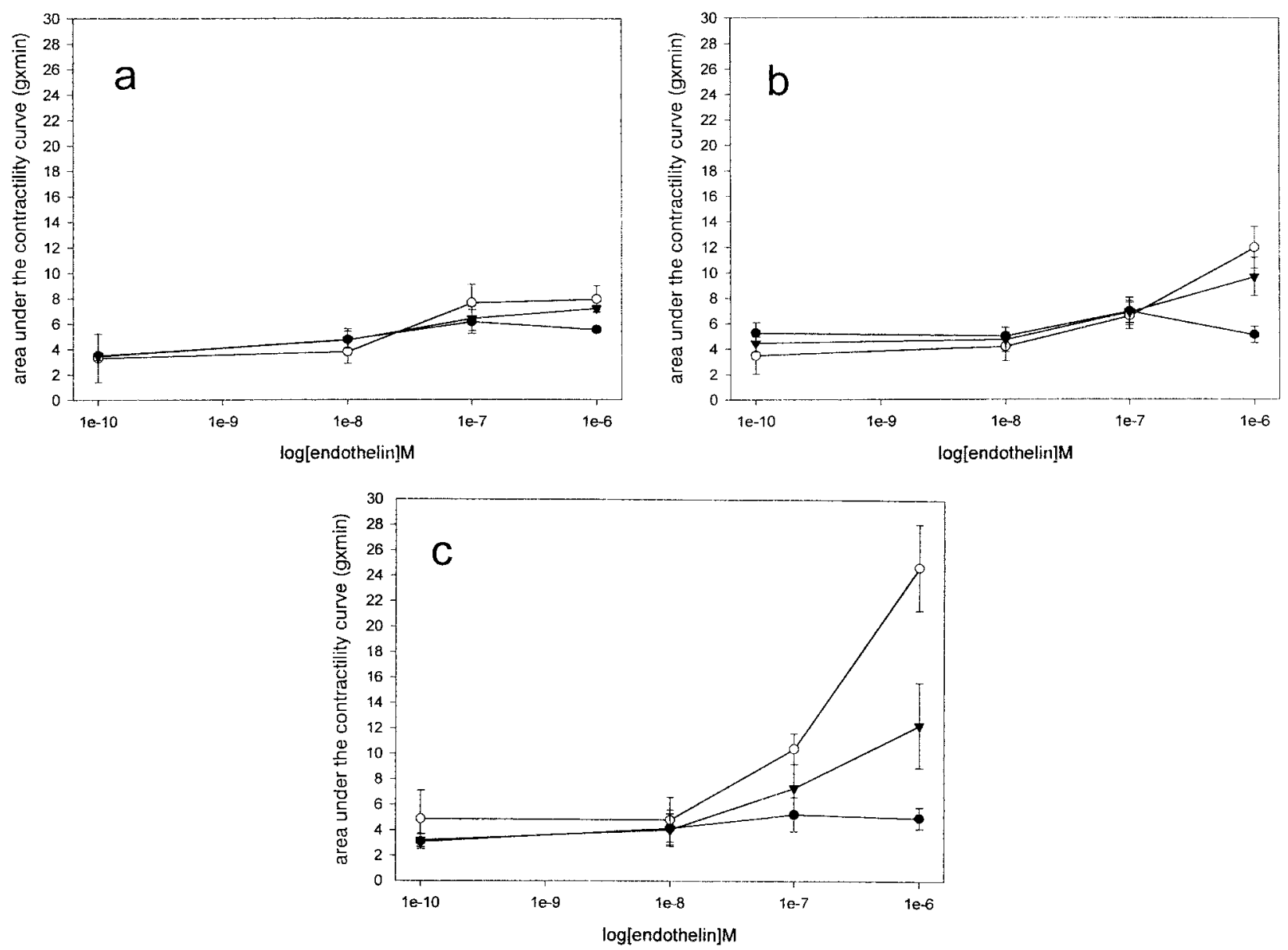

Figure 5 Effect of $\mathrm{KCl}$, ET1 and a combination of $\mathrm{KCl}$ and $\mathrm{ET} 1$ on myometrial contractility (expressed as the AUC) in a period of 10 min after treatment with the stimulus in premenopausal ((a) follicular and (b) luteal) and postmenopausal (c) women; a dose-response effect of ET1 on AUC was found. $\bullet, \mathrm{KCl}, \mathrm{O}, \mathrm{ET} 1, \boldsymbol{\nabla}, \mathrm{KCl}+\mathrm{ET} 1$.

women, but significant differences were also found between the two premenopausal groups. In particular, the pattern of changes in myometrial contractility induced by ET1 in the myometrium from women in the luteal phase was between the patterns of the other two groups. These differences are difficult to explain.

It is known that the contractile effects of ET1 on human nonpregnant myometrium are mediated exclusively by ETA receptors (Bacon et al. 1995, Heluy et al. 1995). The discrepancies in the myometrial responsiveness to ET1 in the three groups observed in the present study could not be attributed to the density or the affinity of the ligand for its receptor as it has already been reported that the binding capacity of ET1 (affinity) does not alter between pre- and postmenopausal women (Schiff et al. 1993, Maggi et al. 1994). Therefore, other mechanisms possibly related to the differentiated hormonal profile of the women may be important. Although individual hormonal values did not correlate significantly with the changes in the contractility induced by the stimuli, it is possible that myometrial contractility to ET1 is enhanced by the estrogen deficiency after menopause, thus explaining the longlasting effect of ET1 seen in group 3. That the pattern of contractility in group 2 was closer to that of group 3 suggests that in terms of responsiveness to the contractile agent, ET1, the myometrium during the luteal phase behaves in a more or less similar manner to that after the menopause. It could be postulated that the counteractive effect of progesterone to estrogen during the luteal phase creates conditions of contractility in the myometrium similar to those in postmenopausal women, but this requires investigation. The intracellular mechanism that could mediate the enhanced responsiveness of estrogendeprived human uterus may be associated with alterations in the receptor's functions leading to changes in the post-receptor biochemical events (Osada et al. 1997).

In the present study, application of $\mathrm{KCl}(80 \mathrm{mM})$ provoked an initial rise in the spontaneous myometrial 

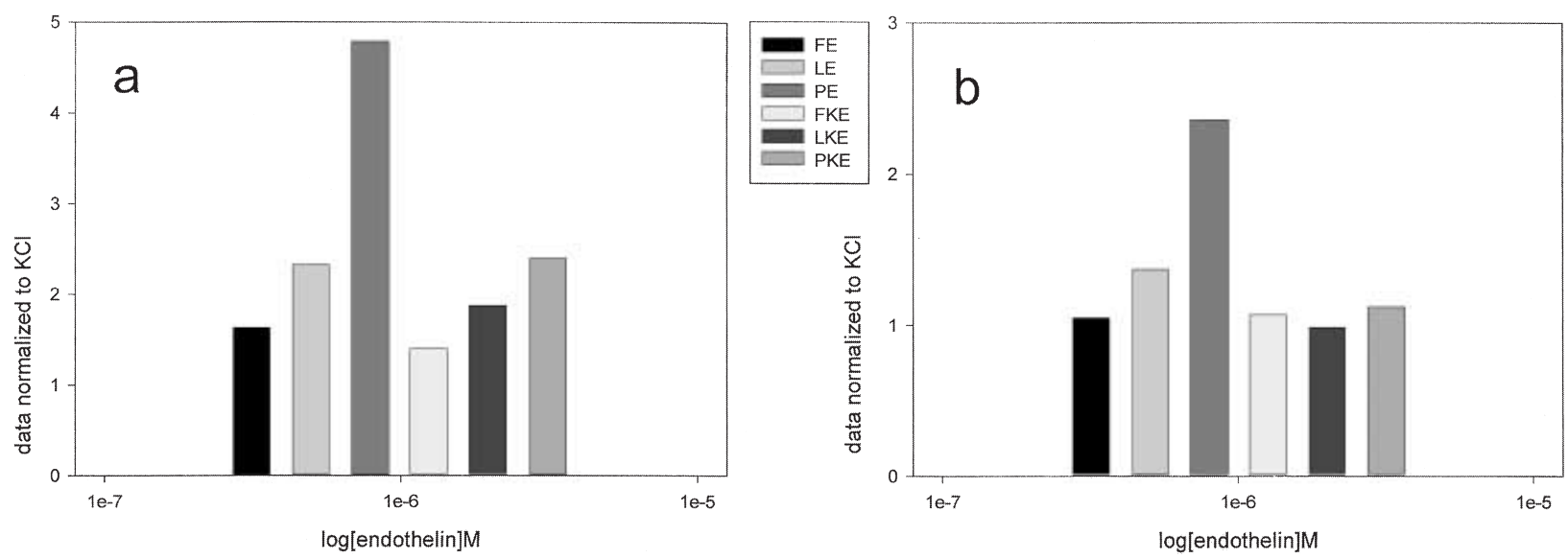

Figure 6 Myometrial responsiveness to ET1 and the combination of $\mathrm{KCl}+\mathrm{ET} 1$ at a concentration $10^{-6} \mathrm{M}$ as shown by (a) the AUC and (b) the amplitude of myometrial contractility. Data were normalized to data obtained after tissue treatment with $\mathrm{KCl}(80 \mathrm{mM})$. $\mathrm{FE}$, follicular phase, ET1; LE, luteal phase, ET1; PE, postmenopausal, ET1; FKE, follicular phase, KCl+ET1; LKE, luteal phase, KCl+ET1; PKE, postmenopausal, $\mathrm{KCl}+\mathrm{ET} 1$.

contractility followed by a relaxation phase to the original baseline without significant differences between the three groups. This means that the responsiveness of the human nonpregnant uterus to $\mathrm{KCl}$ did not alter, despite the change in the hormonal profile of the women, while in pregnant myometrium increased sensitivity to $\mathrm{KCl}$ during the progress of gestation has already been reported (Izumi et al. 1990). The nonchanging responsiveness of nonpregnant human myometrium to $\mathrm{KCl}$ is in contrast to the effect of ET1 that was enhanced in the luteal phase and particularly in the postmenopausal women, thus demonstrating a differential response of human nonpregnant myometrium to ET1 and $\mathrm{KCl}$. Although the addition of ET1 extended significantly the relaxation phase of the $\mathrm{KCl}$-induced contractions in the three groups, basically the pattern of contractility induced by ET1 alone was unaffected by the presence of $\mathrm{KCl}$

The differential response of human uterus to ET1 and $\mathrm{KCl}$ might reflect the involvement of a variety of biochemical mechanisms in the evoked myometrial contractility. A series of studies has already suggested that $\mathrm{KCl}$ induces contractions through voltage-dependent $\mathrm{Ca}^{++}$ influx, which is completely abolished by the presence

Table 2 Mean amplitude values of spontaneous contractions in the three groups before the application of ET1 (first series of experiments) and $\mathrm{KCl}$ plus ET1 (second series of experiments)

\begin{tabular}{llll} 
& ET1 $(\mathrm{g})$ & & $\mathbf{K C l}$ and ET1 $(\mathrm{g})$ \\
Group 1 $(n=6)$ & $1 \cdot 3 \pm 0 \cdot 1$ & & $1 \cdot 4 \pm 0 \cdot 1$ \\
Group 2 $(n=7)$ & $1 \cdot 7 \pm 0 \cdot 2$ & & $1 \cdot 4 \pm 0 \cdot 1$ \\
Group 3 $(n=5)$ & $1 \cdot 4 \pm 0 \cdot 1$ & & $0 \cdot 3 \pm 0 \cdot 1$ \\
\hline
\end{tabular}

of voltage-dependent $\mathrm{Ca}^{++}$channel blockers, such as nifedipine and verapamil (Izumi et al. 1995). In the case of ET1, the dominant requirement and the final event leading to uterine contractility is the increase in the intracellular level of calcium (Word et al. 1990) which is realized, however, not only through voltage-dependent $\mathrm{Ca}^{++}$influx, but also through release of $\mathrm{Ca}^{++}$from intracellular pools and sustained entry of $\mathrm{Ca}^{++}$from receptoroperated $\mathrm{Ca}^{++}$channels (Word et al. 1990, Fried et al. 1993). The latter involves a cascade of events including activation of phospholipase $\mathrm{C}$ and $\mathrm{A}$ and some isoforms of protein kinase C (Xuan et al. 1994, Tertrin-Clary et al. 1999). Continuance of the $\mathrm{Ca}^{++}$supply to the cell could maintain the strength and the duration of the contraction induced by ET1 and could explain the difference in regard to the pattern of myometrial contractility seen with $\mathrm{KCl}$ alone. Additionally, it has been reported that the intact smooth muscle cells show increased sensitivity in terms of contractions to ET1 than $\mathrm{KCl}$ (Himpens \& Casteels 1987).

The physiological importance of the present findings remains to be elucidated. One can postulate that ET1, released by the vascular endothelium or the adjacent endometrium, reaches the myometrium and its vasculature and modifies the spontaneous contractility in a hormonally dependent manner, thus providing an important regulator of uterine function especially in pathological situations such as dysmenorrhea, involved in appearance of ischaemic pain.

In conclusion, the present study demonstrates for the first time differences in the in vitro responsiveness of human nonpregnant myometrium to ET1 between the two phases of the cycle (follicular and luteal) as well as between pre- and postmenopausal women. It is suggested, 
first, that the hormonal milieu may regulate the responsiveness of the myometrium to ET1 at least in in vitro conditions and, secondly, that ET1 and $\mathrm{KCl}$, two uterotonic agents, may regulate myometrial contractility through different mechanisms.

\section{Acknowledgements}

We wish to thank I Makantasis for his technical assistance. This work was supported by a research scholarship to E Domali by the University of Thessaly.

\section{References}

Apa R, Miceli F \& de Feo D 1998 Endothelin-1 inhibits basal and human chorionic gonadotropin-stimulated progesterone production. Human Reproduction 13 2425-2429.

Arai H, Hori S, Aramori I, Ohkubo H \& Nakanishi S 1990 Cloning and expression of a cDNA encoding an endothelin receptor. Nature $348730-732$.

Bacon CR, Morrison JJ, O’Reilly G, Cameron IT \& Davenport 1995 ETA and ETB endothelin receptors in human myometrium characterized by the subtype selective ligands BQ123, BQ3020, FR139317 and PD151242. Journal of Endocrinology 144 127-134.

Bodelsson G, Laursen M \& Stjernquist M 1996 Oxygen promotes contraction by endothelin-1 in human umbilical artery. Human Reproduction 11 2767-2768.

Breuiller-Fouche M, Heluy V \& Fournier T 1994 Endothelin receptors: binding and phosphoinositide breakdown in human myometrium. Journal of Pharmacology and Experimental Therapeutics 270 973-978.

Cameron IT, Davenport AP, van Papendorp C, Barker PJ, Huskisson NS, Gilmour RS, Brown MJ \& Smith SK 1992 Endothelin-like immunoreactivity in human endometrium. Journal of Reproduction and Fertility 95 623-628.

Cameron IT, Plumpton C, Champency R, van Papendorf C, Ashby MJ \& Davenport AP 1993 Identification of endothelin-1, endothelin-2 and endothelin-3 in human endometrium. Journal of Reproduction and Fertility 98 251-255.

Casey ML \& MacDonald PC 1996 The endothelin-parathyroid hormone-related protein vasoactive peptide system in human endometrium: modulation by transforming growth factor-beta. Human Reproduction 11 (Suppl 2) 62-82.

Davenport AP, Ashby MJ, Easton P, Ella S, Bedford J, Dickerson C, Numez DJ, Capper SJ \& Brown MJ 1990 A sensitive radioimmunoassay measuring endothelin-like immunoreactivity in human plasma: comparison of levels in patients with essential hypertension and normotensive control subjects. Clinical Science $\mathbf{7 8}$ 261-264.

Economos K, MacDonald P \& Casey L 1992 Endothelin-1 gene expression and protein biosynthesis in human endometrium: potential modulator of endometrial blood flow. Journal of Clinical Endocrinology and Metabolism 74 14-19.

Elchalal U \& Schenker JG 1997 The pathophysiology of ovarian hyperstimulation syndrome - views and ideas. Human Reproduction 12 1129-1137.

Fried G, Liu YA \& Andersson E 1993 Endothelin contracts human uterine myometrium by a partly dihydropyridine-sensitive mechanism. Acta Physiologica Scandinavica 147 131-136.

Haq A, Kayali M, Hammami MM, Jaroudi K \& al-Sedairy ST 1996 Immunoreactive endothelin-1, endothelin-2 and big endothelin-1 in follicular fluids of women undergoing ovulation induction for in vitro fertilization. Human Reproduction 11 269-273.
Heluy V, Germain G, Fournier T, Ferre F \& Breuiller-Fouche M 1995 Endothelin ETA receptors mediate human uterine smooth muscle contraction. European Journal of Pharmacology 285 89-94.

Himpens B \& Casteels R 1987 Measurement by Quin2 of changes of the intracellular calcium concentration in strips of the rabbit ear artery and of the guinea-pig ileum. Pflügers Archiv 408 32-37.

Izumi H, Ichihara J, Uchiumi Y \& Shirakawa K 1990 Gestational changes in mechanical properties of skinned muscle tissues of human myometrium. American Journal of Obstetrics and Gynecology 163 638-647.

Izumi H, Byam-Smith M \& Garfield RE 1995 Gestational changes in oxytocin- and endothelin-1-induced contractility of pregnant rat myometrium. European Journal of Pharmacology 278 187-194.

Kamada S, Kubota T, Hirata Y, Tagushi M, Egushi S, Marumo F \& Aso T 1992 Direct effect of endothelin-1 on the granuloma cells of the porcine ovary. Journal of Endocrinology 134 59-66.

Kamada S, Kubota T \& Taguchi M 1993 High levels of immunoreactive endothelin-1 in human follicular fluids. Human Reproduction $\mathbf{8}$ 674-677.

Kubota T, Kamada S, Hirata Y, Eguchi S, Imai T, Marumo F \& Aso T 1992 Synthesis and release of endothelin-1 by human decidual cells. Journal of Clinical Endocrinology and Metabolism $\mathbf{7 5}$ $1230-1234$.

Maggi M, Vanelli GB, Fantoni G, Baldi E, Magini A, Peri A, Giannini S, Gloria L, Del Carlo P, Gasparis D et al. 1994 Endothelin in the human uterus during pregnancy. Journal of Endocrinology 142 385-396.

Marciniak SJ, Plumpton C, Barker PJ, Huskisson NS \& Davenport AP 1992 Localization of immunoreactive endothelin and proendothelin in the human lung. Pulmonary Pharmacology 5 175-182.

Marsh MM, Hampton AL, Riley SC, Findlay JK \& Salamonsen LA 1994 Production and characterization of endothelin released by human endometrial epithelial cells in culture. Journal of Clinical Endocrinology and Metabolism 79 1625-1631.

Masaki T, Vane JR \& Vanhoutte PM 1994 International Union of Pharmacology nomenclature of endothelin receptors. Pharmacological Reviews 46 137-142.

Ohkubo S, Ogi K, Hosoya M, Suzuki N, Kimura C, Ondo H \& Fujino M 1990 Specific expression of human endothelin-2 (ET-2) gene in a renal adenocarcinoma cell line. Molecular cloning of cDNA encoding the precursor of ET-2 and its characterization. FEBS Letters 274 136-140.

O'Reilly G, Charnock-Jones DS, Davenport AP, Cameron IT \& Smith SK 1992 Presence of messenger ribonucleic acid for endothelin-1, endothelin-2 and endothelin-3 in human endometrium and a change in the ratio of ETA and ETB receptor subtype across the menstrual cycle. Journal of Clinical Endocrinology and Metabolism 75 1545-1549.

Osada K, Tsunoda H, Miyauchi T, Sughisita Y, Kubo T \& Goto K 1997 Pregnancy increases ET-1-induced contraction and changes receptor subtypes in uterine smooth muscle in humans. American Journal of Physiology 272 R541-R548.

Pekonen F, Nyman T \& Rutanen E-M 1994 Differential expression of mRNAs for endothelin-related proteins in human endometrium, myometrium and leiomyoma. Molecular and Cellular Endocrinology $103165-170$.

Sakurai T, Yanagisawa M, Takuwa Y, Miyazaki H, Kimura S, Goto K \& Masaki T 1990 Cloning of a cDNA encoding a non-isopeptideselective subtype of the endothelin receptor. Nature $\mathbf{3 4 8}$ 732-735.

Sakurai T, Yanagisawa M, Inoue A, Ryan US, Kimura S, Mitsui Y, Goto K \& Masaki T 1991 cDNA cloning, sequence analysis and tissue distribution of rat preproendothelin-1 mRNA. Biochemical and Biophysical Research Communications 175 44-47.

Sakurai T, Yanagisawa M \& Masaki T 1992 Molecular characterization of endothelin receptors. Trends in Pharmacological Sciences 13 103-108. 
Salamonsen LA, Butt AR, Macpherson AM, Rogers P \& Findlay JK 1992 Immunolocalization of the vasoconstrictor endothelin in human endometrium during the menstrual cycle and in umbilical cord at birth. American Journal of Obstetrics and Gynecology 167 163-167.

Schiff E, Ben-Baruch G, Galron R, Mashiach S \& Sokolovsky M 1993 Endothelin-1 receptors in the human myometrium: evidence for different binding properties in post-menopausal as compared with premenopausal and pregnant women. Clinical Endocrinology 38 321-324.

Sunnergen KP, Word RA, Sambrook JF, MacDonald PC \& Casey ML 1990 Expression and regulation of endothelin precursor mRNA in avascular human amnion. Molecular and Cellular Endocrinology 68 R7-R14.

Svane D, Larsson B, Alm P, Andersson KE \& Forman A 1993 Endothelin-1: immunocytochemistry, localization of binding sites, and contractile effects in human uteroplacental smooth muscle. American Journal of Obstetrics and Gynecology 168 233-241.

Tertrin-Clary C, Eude L, Fournier T, Paris B, Breuiller-Fouche M \& Ferre F 1999 Contribution of protein kinase C to ET1-induced proliferation in human myometrial cells. American Journal of Physiology 276 E503-E511.

Wolff K, Faxen M, Lunell NO, Nisell H \& Lindblom B 1996 Endothelin receptor type $\mathrm{A}$ and $\mathrm{B}$ gene expression in human nonpregnant, term pregnant, and preeclamptic uterus. American Journal of Obstetrics and Gynecology 175 1295-1300.

Word RA, Kamm KE, Stull JT \& Casey ML 1990 Endothelin increases cytoplasmic calcium and myosin phosphorylation in human myometrium. American Journal of Obstetrics and Gynecology $1621103-1108$.

Word RA, Kamm KE \& Casey L 1991 Contractile effects of prostaglandins, oxytocin and endothelin-1 in human myometrium in vitro: refractoriness of myometrial tissue of pregnant women to prostaglandins $\mathrm{E}_{2}$ and $\mathrm{F}_{2 \alpha}$. Journal of Clinical Endocrinology and Metabolism 75 1027-1032.

Xuan Y-T, Wang O-L \& Whorton AR 1994 Regulation of endothelin-induced $\mathrm{Ca}^{2+}$ mobilization in smooth muscle cells by protein kinase C. American Journal of Physiology 266 c1560-c1567.

Yanagisawa M, Kurihara H, Kimura S, Goto K \& Masaki T 1988 A novel peptide vasoconstrictor, endothelin 1 , is produced by vascular endothelium and modulates smooth muscle $\mathrm{Ca}^{2+}$ channels. Journal of Hypertension Supplement 6 188-191.

Received 19 May 2000

Revised manuscript received 10 August 2000 Accepted 20 September 2000 